\begin{abstract}
Early childhood intervention (ECI) services for children on the autism spectrum commonly espouse a family-centred approach but outcomes studies often focus solely upon the child. Mothers of 96 children on the spectrum (aged 4-5) completed a measure of access to ECI and the Family Outcomes Survey-Revised. Family outcomes after ECI were generally positive, although a notable proportion of mothers rated that their child still did not participate in social, recreational, or religious activities that they would want to $(15.6 \%)$ and that as parents, they did not know about post-ECI options (14.6\%). Family outcomes and perceived helpfulness of ECI did not differ with demographic data with the exception of Accessing the community subscale which was significantly higher in families with incomes above
\end{abstract} AUD\$80,000.

Keywords: autism, mothers, early intervention, family outcomes 


\section{Family outcomes for families of 4-5-year-old children on the autism spectrum who have received early childhood intervention in Australia}

Earlier identification and diagnosis of autism in children has resulted in an increased focus on the provision of effective early childhood intervention (ECI). ECI comprises (a combination of) evidence-based interventions within the early childhood years (typically 0-6 years old) to promote function, increase a child's developmental capabilities and prevent secondary impairments. These interventions are focused on enabling individuals to achieve and maintain optimal functioning and participation at home as well as within the community (see review by Odom \& Wolery, 2003).

\section{Early Childhood Intervention and Family-Centered Services}

Research aiming to identify the effective elements of ECI for autism consistently identifies behavioural and educational approaches as offering the best evidence for improved outcomes, whilst also emphasising the central role of parents in the implementation of such interventions (see review by Zwaigenbaum et al., 2015). Family systems theory recognises the interrelatedness of parents and their children and that the needs of all members must be recognised and addressed. Parents of children with autism may find themselves primarily in the role of an ECI implementer, particularly given parent-mediated interventions have become more widespread (Vivanti et al., 2017), which can then intensify the focus of attention on child outcomes. Whilst child outcomes are clearly important, Bailey et al. (2011) argue that a narrow focus on child outcomes is not sufficient for determining the outcomes of ECI. Such a narrow focus ignores parent and family factors that potentially influence the proximal and distal effects of intervention, with an implicit assumption that positive child outcomes of ECI will translate to positive outcomes for parents and families (Karst \& Van Hecke, 2012). Given the vital role of parents and families in supporting and advocating for 
their child across a range of environments and transitions, including transitioning from ECI programs to schooling, the impact and perceived benefits of ECI on parents and the whole family warrants consideration.

Family-centred services (FCS) recognise the knowledge, stability, and longevity of family members within the child's system and therefore aim to build capacity within the family to optimise the child's development (Dempsey, Keen, Pennell, O'Reilly, \& Neilands, 2009). Dempsey and Keen (2008) state that definitions of FCS vary, but FCS share four key beliefs (1) that the family, not the professional, is the constant in the child's life (2) the family is in the best position to determine the needs and well-being of the child (3) the child is best helped by also helping the family, and this help may extend to an understanding of the family's community and to providing information that the family needs and (4) family choice and decision making in the provision of services, showing respect and affirming families' strengths, enhancing family control over the services they receive, and partnerships and collaborations with families are emphasized (Dunst, 2002; Duwa, Wells, \& Lalinde, 1993). FCS are associated with an increased sense of family well-being, better engagement with services and between family members, and improved health or developmental outcomes for children (Dunst, 2000; McBroom \& Enriquez, 2009; Piotrowski, Talavera, \& Mayer, 2009). Family-centred approaches are the cornerstone of ECI, with family members playing a critical role within and beyond the intervention (Bailey et al., 2006; Bailey et al., 2008; Bruder, 2010). Parenting competence and confidence are identified as outcomes from FCS and are often hypothesised to lead to improvements in child functioning (Dempsey, et al., 2009). However, there is limited research exploring parenting competence and confidence in relation to ECI (e.g. Heller, Miller, \& Hsieh, 1999; Keen, Rodgers, Couzens, \& Muspratt, 2010), highlighting the need for more work in this area.

\section{Measuring Outcomes of Early Childhood Intervention}


Typically, ECI services are assessed by measuring parent satisfaction, but despite numerous studies in this area across the past two decades (e.g., Bailey, Hebbeler, Olmsted, Raspa, \& Bruder, 2008; Lanners \& Mombaerts, 2000; McIntyre \& Zemantic, 2016; McNaughton, 1994), parent satisfaction remains notoriously difficult to measure (Sarimski, Hintermair, \& Lang, 2013). Difficulties in measurement arise largely from the subjective nature of satisfaction, whereby the construct is affected by a person's emotions (Crow et al., 2002) and influenced by expectations (Lanners \& Mombaerts, 2000), for example, expectations of what could or should have been offered by a service. Parents may feel reluctant to report dissatisfaction with a service for fear of it being withdrawn or may feel pressure to engage positively with many interventions in order to maximise outcomes, thus increasing parental stress (Shepherd, Landon, \& Goedeke, 2017). However, it is imperative to consider broader benefits received by families as a result of ECI, rather than simply evaluating parental satisfaction.

Given that FCS are the cornerstone of ECI, another way of measuring outcomes of ECI and FCS is by measuring the broader benefits, including Family Outcomes. Bailey \& Bruder (2005) describe a Family Outcome as "a benefit experienced by families as a result of services received... a family outcome is not the receipt of services, but something that happens because services or supports are provided". An example of a Family Outcome may be providing parents with information about the characteristics of autism which the parents understand and then find helpful in describing autism to others, to advocate for services, or respond effectively to their child's behavioural presentation. Poon, Ooi, Bull, and Bailey (2014) evaluated family outcome measures, noting that until Bailey et al.'s (2006) study of U.S. national stakeholder inputs, the concept of family outcomes of ECI was not specifically defined, with a range of studies have suggesting up to eleven ways to conceptualise family outcomes (see review by Bailey \& Bruder, 2005). This lack of specification led to the 
creation of the Family Outcomes Survey (FOS; Bailey et al., 2006), later amended to the Family Outcomes Survey - Revised (FOS-R; Bailey et al., 2011). The key

conceptualisations of family outcomes assessed within the FOS-R are families (1) knowing their child's strengths, needs and abilities (2) knowing their rights and advocating for their child (3) helping their child to develop and learn (4) having support systems and (5) accessing the community.

The FOS/FOS-R, in combination with other measures including the Family Needs Survey (FNS; Bailey \& Simeonsson, 1988) and the Family Quality of Life scale (FQOL; Hoffman, Marquis, Poston, Summers, \& Turnbull, 2006), has contributed significantly to the understanding of families in ECI within the United States. However, work outside of the United States to date has been scarce. Studies investigating the FOS-R in Singaporean and Japanese populations (Poon et al., 2014; Ueda, Yonemoto, \& Bailey, 2015) hypothesised that cultural differences (including those relating to healthcare and ECI provision) may impact upon reported family outcomes. Studies to date have also tended to focus upon samples with a mixed aetiology of disabilities, despite findings that perceived outcomes of ECI differ between different diagnoses (e.g., Gavidia-Payne, Meddis, \& Mahar, 2015). The aim of this study was to expand upon the description of the previously reported studies of family outcomes from ECI in America, Singapore and Japan, by being the first study to report on the family outcomes of families of children on the autism spectrum in Australia.

\section{ECI services for children on the autism spectrum in Australia}

The historical and current provision of ECI in Australia is summarised by Sukkar (2013). In brief, children from birth to six years who experience a developmental delay or disability, including children on the autism spectrum, can access ECI services. These services may include specialist teaching and therapeutic interventions delivered in a variety of modalities such as home visits, preschool or school consultations (Hughes-Scholes, Gatt, 
Davis, Mahar \& Gavidia-Payne, 2016). Medicare, the national body that subsidises primary health care in Australia, provides specific plans which entitle children on the autism spectrum to access sessions with a Psychologist, Speech Therapist, Occupational Therapist, Audiologist, Optometrist, Orthoptist or Physiotherapist, with some plans (such as the Chronic Disease Management Plan) having an annual allowance of sessions and others (such as the Helping Children with Autism Treatment Plan) having a lifetime allowance. In addition to these Medicare plans, in order to address the increased number of children receiving a diagnosis on the autism spectrum, in 2008, Australia introduced a national funding scheme called the Helping Children with Autism Package (HCWA). Funding was a set amount (AUD\$12,000) to cover interventions, ECI programs, disability-specific playgroups, and speech or other therapies such as occupational therapy, for young children (aged 0-6) on the autism spectrum. The funding was not sufficient to fund full-time early intensive behavioural intervention (EIBI) or other intensive programs, but some families chose to top-up their package independently or with their private medical insurance to fund such interventions, while others opted for an eclectic, non-intensive ECI approach. More recently, the National Disability Insurance Scheme (NDIS), that will replace HCWA and various other disability funding programs, is being introduced across Australia. The NDIS provides support for individuals aged 0-65 years using an individualised and lifelong approach to funding. The amount of funding varies and is based upon individual needs, goals and aspirations. The focus of the NDIS is on giving families choice and control. This means that families will be able to select the range and providers of interventions, including ECI for younger children, and provides ongoing support to enable older children with disabilities to participate in their communities.

Given the growing focus on the importance of ECI for autism and government support to access services in Australia and elsewhere, coupled with the recognised 
importance of measuring family outcomes of ECI, this study explored the following research questions in a sample of families of children on the spectrum in Australia:

1. To what extent are family outcomes of ECI, as assessed by items on the FOS-R, attained by families of children on the autism spectrum who have participated in ECI services in Australia?

2. To what extent do mothers of children on the autism spectrum in Australia perceive ECI services to have contributed towards these outcomes?

\section{Methods}

\section{Data source and sample}

This study used data extracted from Time 1 of the Longitudinal study of Australian Students with Autism (LASA), an ongoing six-year sequential study (see Roberts et al., 2018 for details and the full protocol). The LASA is one study within the Cooperative Research Centre for Living with Autism (Autism CRC), established and supported under the Australian Government's Cooperative Research Centres Program.

Children who met the two inclusion criteria (a confirmed autism spectrum diagnosis and being aged 4-5 or 9-10) across Australia were invited to participate through community service providers, education and health services and social media. Potential participants were provided with information about the study by practitioners and services and those who wished to participate completed the online consent form and Time 1 questionnaire. The sample was therefore self-selecting and for reasons of confidentiality, the research team was not provided with any details on children or families who received the information but did not enroll into the study. As part of this sequential study, parents provide data annually through a range of developmental and educational assessments. Ethical approval for this study was obtained from participating universities and health authorities. 
As this paper centres on recent family experiences of ECI and parents' perceptions of the helpfulness of ECI, only participants within the younger cohort of the larger study (who were 4-5 years at time of recruitment, $n=132$ ) were of interest. All children whose caregivers had (a) completed the Social Communication Questionnaire (SCQ; Rutter, Bailey, Berument, Lord, \& Pickles, 2003) and received a cut-off score of $\geq 11$ for autism screening (Lee, David, Rusyniak, Landa, \& Newschaffer, 2007), (b) stated that their child had received ECI, and (c) fully completed the FOS-R were included in this study $(n=96)$. To explore whether these participants were representative of the larger sample from which they were drawn, comparisons were made between those who did and did not meet the inclusion criteria for this study. The sample of 96 children described within this study did not differ from the remaining 36 children who did not meet the inclusion criteria in prevalence of parentreported mental health diagnoses $\left(\chi^{2}(2)=1.9, p=.39\right)$, highest level of parent education $\left(\chi^{2}(1)=0.29, p=.59\right)$, parent occupation $\left(\chi^{2}(2)=1.1, p=.59\right)$, or household income $\left(\chi^{2}(4)=9.4, p=.05\right)$. The two groups did differ in terms of distribution of child gender $\left(\chi^{2}(1)=4.4, p=.04\right)$, with $12(12.5 \%)$ of the sample within the paper and $10(27.8 \%)$ of the excluded sample being female. Three of the ten females were excluded due to SCQ scores below 11, three because their daughter had not received early intervention, three because the respondent was the child's father (and this study focussed upon mothers) and one because they had not provided complete data on the FOS-R.

Demographic information for the 96 participants within this paper (both children and their caregivers) is provided in Table 1. 
Table 1

Child and Caregiver Characteristics $(\mathrm{N}=96)$

Demographic variables $\quad \mathrm{N}(\%)$

$\begin{array}{ll}\text { Child gender: Male } & 84(87.5)\end{array}$

Other medical condition/disability 41 (42.7)

Caregiver's age

$<30$ years

$13(3.5)$

$31-40$ years

$59(61.5)$

$41-50$ years

$22(22.9)$

Did not disclose

$2(2.1)$

Caregivers with tertiary education or above

$76(79.2)$

Caregiver diagnosis of mental health disorder

$24(25)$

(lifetime)

Caregiver diagnosis of autism spectrum disorder

$6(6.3)$

Caregiver's occupation

Employed (full- or part-time)

$51(53.1)$

Studying (full- or part-time)

$13(13.5)$

Caring responsibilities

$31(32.3)$

Annual family income

$<\$ 18,200$

$6(6.3)$

$\$ 18,201-\$ 37,000$

$6(6.3)$

$\$ 37,001-\$ 80,000$

$23(24.0)$

$\$ 80,001-\$ 180,000$

$49(51.0)$

$>\$ 180,000$

$8(8.3)$

Do not wish to respond

$4(4.2)$ 
The average age of the children was 60.4 months and the average age of receiving an autism diagnosis was 40.7 months (sd 11.0, range 17-65 months). In addition to a diagnosis of autism, $42.7 \%$ of the children had a parent-reported additional diagnosis of another medical condition or disability. The most frequently listed comorbid diagnoses were Attention Deficit Hyperactivity Disorder (ADHD; n=11, 11.5\%), Global Developmental Delay or and Intellectual Disability (GDD/ID; $n=5,5.2 \%)$, Oppositional Defiant Disorder (ODD; $n=4,4.2 \%)$, anxiety ( $n=3,3.1 \%)$, Sensory Processing Disorder (SPD, $n=3,3.1 \%$ ), hearing issues $(n=3,3.1 \%)$ and epilepsy $(n=3,3.1 \%)$. The questionnaires were all completed by mothers, whose first language was English. The majority of mothers had a tertiary education; for reference, the 2016 Australian Census noted that $30.9 \%$ of the population had studied for and achieved educational qualifications of diploma or above. Within this sample, almost $60 \%$ had a family income of AUD\$80,000 or above; the 2016 Australian Census reported the median Australian annual family income to be AUD \$90,168.

\section{Measures}

Demographics and intervention questionnaire. A purpose-designed questionnaire was administered that included demographic questions related to the child and caregiver, and questions regarding the amount and type of ECI strategies the child had received.

Family Outcomes Survey measure. Mothers completed the FOS-R. This 41 -item questionnaire assesses core family outcomes (Part A) and perceived helpfulness of early intervention (Part B) for families of children with disabilities. Part A has 24 items which ask about the ways in which families support their child's needs. Questions are grouped into five outcomes: (a) understanding your child's strengths, needs, and abilities; (b) knowing your rights and advocating for your child; (c) helping your child develop and learn; (d) having 
support systems; and (e) accessing the community. Each item in this section is rated from 1 (not at all) to 5 (completely).

Part B asks mothers to focus on how helpful ECI has been over the previous year, with three outcomes: (a) knowing and understanding their rights, (b) communicating their children's needs, and (c) helping their children develop and learn. Each question is rated between 1 (not at all helpful) to 5 (extremely helpful). Mean scores are calculated for each outcome, along with an overall total for each section. Bailey et al. (2011) demonstrated high internal consistency for the five FOS-R family outcomes ( $\alpha$ range from .73-.91) and the three helpfulness indicators ( $\alpha$ range from .90-.94). Ueda et al. (2015) also found high correlations between outcome subscale scores and full-scale scores. Within this sample, Cronbach's alphas for Section A were: .86 for understanding your child's strengths, needs, and abilities; .87 for knowing your rights and advocating for your child; .88 for helping your child develop and learn; .81 for having support systems; and .76 for accessing the community. For Section B, Cronbach's alphas were: .93 for knowing your rights, .92 for communicating your child's needs, and .97 for helping your child develop and learn.

\section{Data analysis}

SPSS 24 was used for data analysis. The interventions and funding streams accessed by mothers and their associations with family variables (level of parent education and family income) were explored using a t-test and Spearman's correlation. The proportion of mothers giving different ratings for each question within an outcome is presented for both Section A and Section B. A series of Analyses of Variance (ANOVA) were undertaken to compare the subscale FOS-R scores dependent upon child gender, parental education, family income (above/below AUD\$80,000) and maternal mental health diagnosis (present/absent). Alpha was set to .001 to correct for the multiple comparisons. 


\section{Results}

\section{ECI Use}

All children in the study had accessed either intensive or occasional, home, or centrebased ECI programs, or received private therapy. Sixty-seven (69.8\%) children had received autism-specific ECI programs, either home, school, or centre based. As shown in Table 2, $82.3 \%$ of children were receiving private speech pathology and $82.3 \%$ were receiving private occupational therapy. Eight $(8.33 \%)$ mothers stated that they had not received financial support for interventions from the Helping Children with Autism funding scheme or the NDIS. 
Table 2.

Early Childhood Interventions Reported to be Accessed across the Sample

\begin{tabular}{|c|c|}
\hline Intervention & $\begin{array}{l}\mathrm{N}=96 \\
\mathrm{~N}(\%)\end{array}$ \\
\hline Attendance at autism-specific school (with intervention) & $11(11.5)$ \\
\hline Centre-based early childhood intervention program: & $32(33.3)$ \\
\hline \multicolumn{2}{|l|}{ Occasional } \\
\hline Centre-based early childhood intervention program: & $20(20.8)$ \\
\hline \multicolumn{2}{|l|}{ Intensive/Full-time } \\
\hline Home-based early childhood intervention program: & $20(20.8)$ \\
\hline \multicolumn{2}{|l|}{ Occasional } \\
\hline Home-based early childhood intervention program: & $12(12.5)$ \\
\hline \multicolumn{2}{|l|}{ Intensive/Full-time } \\
\hline Private speech pathology sessions & $79(82.3)$ \\
\hline Private psychology sessions & $35(36.5)$ \\
\hline Private occupational therapy sessions & $79(82.3)$ \\
\hline \multicolumn{2}{|l|}{ Number of early childhood intervention strategies (listed } \\
\hline \multicolumn{2}{|l|}{ above) used } \\
\hline 1 & $8(8.3)$ \\
\hline 2 & $21(21.9)$ \\
\hline 3 & $35(36.5)$ \\
\hline 4 & $25(26.0)$ \\
\hline 5 & $6(6.3)$ \\
\hline 6 & $1(1)$ \\
\hline Received Helping Children with Autism funding & $85(88.5)$ \\
\hline Received NDIS funding & $9(9.4)$ \\
\hline
\end{tabular}


Almost all mothers reported their child being engaged in multiple intervention approaches, with $84.4 \%$ of mothers reporting current engagement in between two and four of the seven options presented in the questionnaire (as listed in Table 2). There was no association between family income and the number of interventions from the list being used $($ rho $=.09, p=.39)$, nor was there any difference based upon level of maternal education $(t(94)=-.61, p=.54)$

\section{Family Outcomes}

Item level data Section A. Section A of the FOS-R focuses upon the mothers' perceptions of their competence, confidence, and ability to care for their child. Figure 1 outlines the response profile for each item within Section A and Table 3 reports the means and standard deviations of the total sample. 


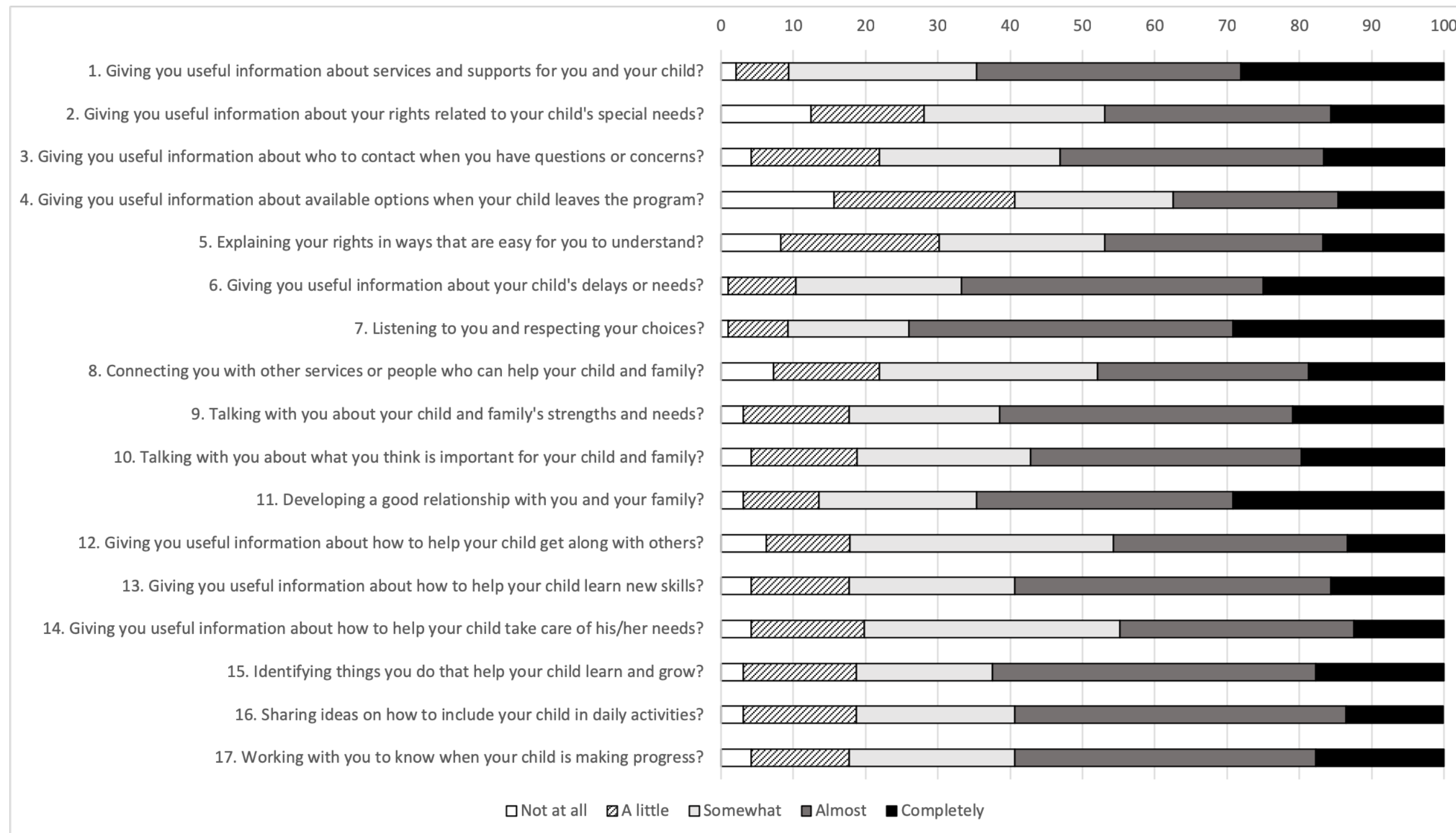


All the items had a comparatively high proportion of positive responses, with very few respondents rating not at all for the items. The items with the highest rating for not at all were Item 8 ("We know what options are available when our child leaves the current program”; 14.6\%) and Item 19 (“Our child participates in social, recreational, or religious activities that we want"; $15.6 \%$ ). The items with the highest ratings for completely were Item 23 ("Our transportation needs are met"; 78.1\%) and Item 24 ("Our food, clothing, and housing needs are met”; 78.1\%).

There was variability both across items and within the outcomes, highlighting the importance of considering the data at item level. For example, Outcome 5 (Accessing the Community) had items with both the highest and lowest levels of endorsement for always. The results of Outcome 4 (Having Support Systems) highlighted that, although over half of the mothers rated that they almost or completely had friends or family that they feel comfortable talking to, who listen and care, who have similar needs, and whom they can rely on, only $22.9 \%$ of mothers were able to take care of their own needs and do things they enjoyed almost or completely.

Table 3.

Mean and SD of items from FOS-R Section A: Core Family Outcomes (N=96)

\begin{tabular}{lcc}
\hline Item: Which describes your family right now? $(1=$ not at all, 5= completely) & $\bar{x}$ & SD \\
\hline 1. We know the next steps for our child's growth and learning. & 3.68 & .91 \\
2. We understand our child's strengths and abilities. & 4.08 & .76 \\
3. We understand our child's delays and/or needs. & 4.18 & .81 \\
4. We able to tell when our child is making progress. & 4.31 & .73 \\
5. We are able to find and use the services and programs available to us. & 3.84 & .86 \\
6. We know our rights related to child's special needs. & 3.45 & 1.03
\end{tabular}


7. We know who to contact and what to do with questions or concerns.

8. We know what options are available when child leaves the current program. $\quad \begin{array}{lll}2.99 & 1.24\end{array}$

9. We are comfortable asking for services \& supports that our child and family $\quad 3.88 \quad 1.05$ need.

10. We are able to help child get along with others.

11. We are able to help child learn new skills $4.07 \quad .76$

12. We are able to help child take care of his/her needs

13. We are able to work on child's goals during everyday routines.

14. We are comfortable talking to family and friends about child's needs.

15. We have friends or family members who listen and care.

16. We are able to talk with other families who have a child with similar needs.

17. Have friends or family members we can rely on when we need help.

18. I am able to take care of my own needs and do things I enjoy.

19. Our child participates in social, recreational, or religious activities that we want.

20. We are able to do things we enjoy together as a family.

21. Our medical and dental needs are met.

22. Our child care needs are met.

23. Our transportation needs are met.

Item level data Section B. Section B of the FOS-R focuses upon the degree to which the mothers perceived ECI to be helpful and supportive across 17 areas. Figure 2 outlines the response profile for each item within Section B and Table 4 reports the means and standard deviations of the total sample. 
1. We know the next steps for our child's growth and learning.

2. We understand our child's strengths and abilities.

3. We understand our child's delays and/or needs.

4. We are able to tell when our child is making progress.

5. We are able to find and use the services and programs available to us.

6. We know our rights related to our child's special needs.

7. We know who to contact and what to do when we have questions or concerns.

8. We know what options are available when our child leaves the current program.

9. We are comfortable asking for services \& supports that our child and family...

10. We are able to help our child get along with others.

11. We are able to help our child learn new skills.

12. We are able to help our child take care of his/her needs.

13. We are able to work on our child's goals during everyday routines.

14. We are comfortable talking to family and friends about our child's needs.

15. We have friends or family members who listen and care.

16. We are able to talk with other families who have a child with similar needs.

17. We have friends or family members we can rely on when we need help.

18. I am able to take care of my own needs and do things I enjoy.

19. Our child participates in social, recreational, or religious activities that we want.

20. We are able to do things we enjoy together as a family.

21. Our medical and dental needs are met.

22. Our child care needs are met.

23. Our transportation needs are met.

24. Our food, clothing, and housing needs are met.

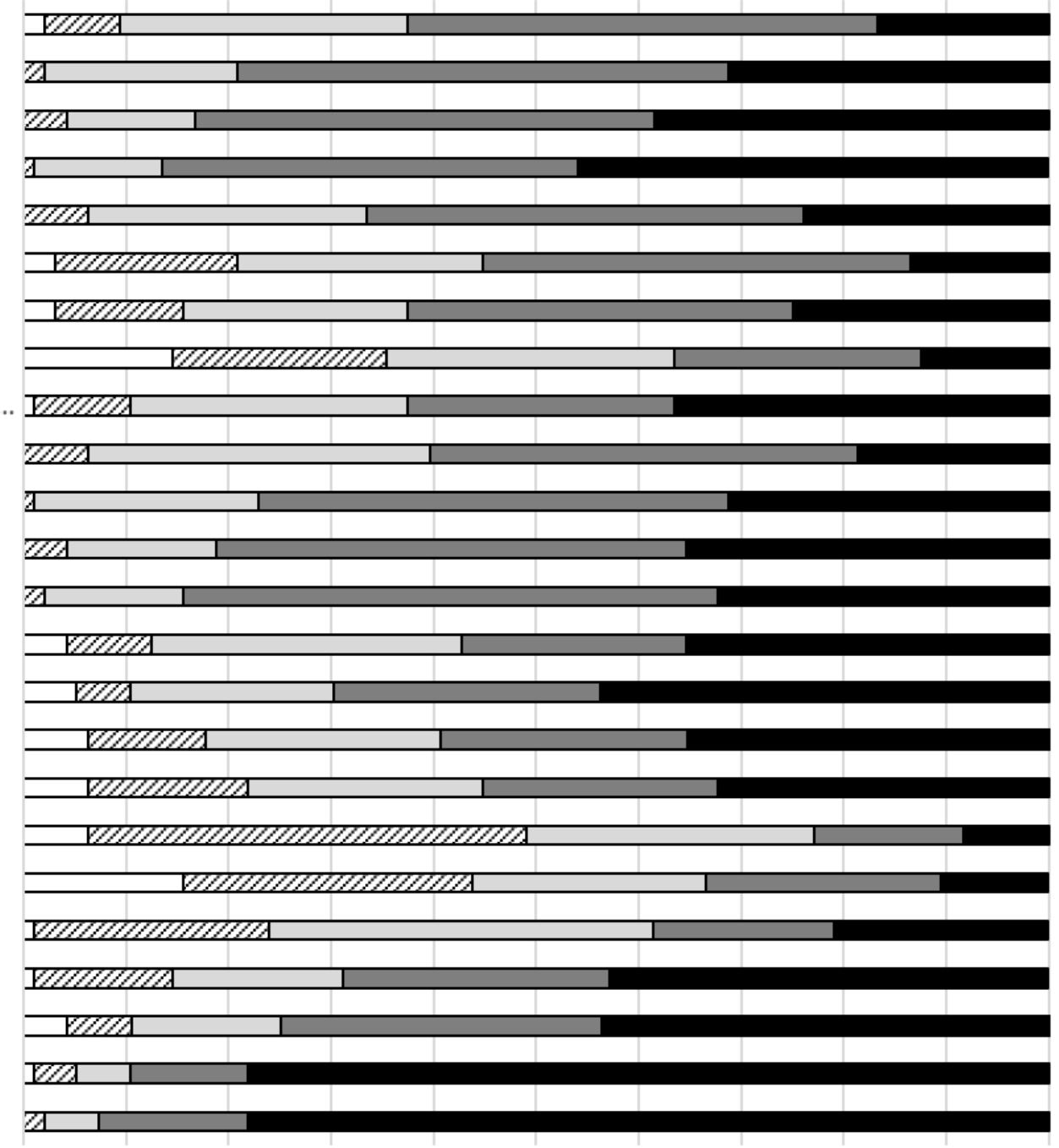

$\square$ Not at all $\square$ Alittle $\square$ Somewhat $\square$ Almost $\square$ Completely 
Items in Section B also had a higher proportion of positive ratings, with between $1 \%$ and $15.6 \%$ of mothers rating not at all compared to $13.5 \%$ to $29.2 \%$ of mothers rating completely. Over two thirds of mothers rated the ECI services as almost or completely helpful at providing them with information about their child's delays and needs and listening to them and respecting their choices. The items that most mothers rated ECI services as being completely helpful in were Item 11 ("Developing a good relationship with you and your family"; 29.2\%) and Item 1 ("Giving you useful information about services and supports for you and your child"; $28.1 \%$ ). The two items with the highest proportion of mothers rating not at all were Item 2 ("Giving you useful information about your rights related to your child's special needs"; $12.5 \%$ ) and Item 4 ("Giving you useful information about available options when your child leaves the program"; $15.6 \%$ ).

Subscale data

Due to differing numbers of items per subscale, the mean score per question was calculated to allow for comparisons. Within section A, the subscale with the highest mean score was Outcome 1 "Understanding your child's strengths, needs and abilities" $(\overline{\mathrm{x}}=4.06$, $s d=.68)$ and the lowest was Outcome 4 "Having support systems" $(\overline{\mathrm{x}}=3.56, s d=.89)$. Within section B (which focuses upon perceived helpfulness of ECI), the subscale with the highest mean score was Helpfulness Indicator 2 "Communicating your child's needs" ( $\mathrm{x}=$ $3.67, s d=.89)$ and the lowest was Helpfulness Indicator 1 "Knowing your rights" $(\overline{\mathrm{x}}=3.34$, $s d=1.04)$

Table 4.

Mean and SD of items from FOS-R Section A: Perceived helpfulness of early intervention $(\mathrm{N}=96)$

Item: How helpful has early intervention been for you are your family in the $\quad \bar{x}$ SD
past year in.... (1 = not at all helpful, $5=$ extremely helpful $)$


1. Giving you useful information about services and supports for you and your $3.81 \quad 1.00$ child?

2. Giving you useful information about rights related to your child's special $\quad \begin{array}{lll}3.22 & 1.25\end{array}$ needs?

3. Giving you useful information about who to contact with questions or $\quad 3.44 \quad 1.09$ concerns?

4. Giving you useful information about available options when your child $\quad 2.96 \quad 1.31$ leaves the program?

5. Explaining your rights in ways that are easy to understand? $\quad 3.25 \quad 1.21$

$\begin{array}{lll}\text { 6. Giving you useful information about your child's delays or needs? } & 3.80 \quad 96\end{array}$

$\begin{array}{lr}\text { 7. Listening to you and respecting your choices? } & 3.93 \quad 94\end{array}$

8. Connecting you with other services or people who can help your child and $\quad 3.38 \quad 1.16$ family?

9. Talking with you about your child and family's strengths and needs? $\quad 3.61 \quad 1.07$

10. Talking with you about what you think is important for your child and $\quad 3.54 \quad 1.09$ family?

11. Developing a good relationship with you and your family?

$3.77 \quad 1.08$

12. Giving you useful information about how to help your child get along with $3.35 \quad 1.06$ others?

13. Giving you useful information about how to help your child learn new $\quad 3.53 \quad 1.05$ skills?

14. Giving you useful information about how to help your child take care of $\quad \begin{array}{lll}3.33 & 1.02\end{array}$ his/her needs?

15. Identifying things you do that help your child learn and grow? $\quad 3.58 \quad 1.05$

16. Sharing ideas on how to include your child in daily activities? $\quad 3.51 \quad 1.02$

17. Working with you to know when your child is making progress? $\quad 3.551 .06$

Family outcomes based on family demographics. In order to explore if family outcomes differed dependent upon demographic variables, a series of Analyses of Variance (ANOVA) were undertaken. There were no significant differences on family outcomes (Part A) or perceived helpfulness of ECI (part B) dependent upon parental employment status, mental health diagnosis or child gender. Families with an income above AUD $\$ 80,000$ per annum had significantly higher scores $\left(\mathrm{F}(1,90)=4.61, p=.001, \eta p^{2}=.11\right)$ on the Section A "Accessing the community" outcome $(\overline{\mathrm{x}}=4.08, s d=.60)$ than those who reported a family 
income below AUD $\$ 80,000$ per annum $(\overline{\mathrm{x}}=3.62, s d=.72)$. There were no significant differences based on family income on any of the other Part A outcomes or perceived helpfulness of ECI.

\section{Discussion}

This is the first study to explore the profile of scores for items of the FOS-R in a sample of children on the autism spectrum and the first to report on the FOS-R in Australian children on the spectrum. It therefore a valuable contribution to our knowledge about family outcomes in this context and highlights the importance of considering families, rather than just child outcomes, when evaluating ECI services.

The subscale comparisons highlight where mothers report feeling more and less competent. Interestingly, for both section A and section B, the standard deviations were smallest for the highest subscale scores and largest for the lowest subscale scores. This indicates larger variability in answers for the subscales of "Having support systems" and "Knowing your rights". The comparisons of subscale scores based upon demographic data suggest that family outcomes do not differ based upon parental education, mental health diagnosis and child gender and that only one family outcome (accessing the community) differed based on family income. Future studies should explore predictors in more detail, including factors such as child ability and behaviour which have been shown to impact upon parental well-being and coping strategies as well as use of support services (Adams, Hastings et al., 2018; Adams, Handley et al., 2018).

The items in Section A of the FOS-R provide an overview of ways in which mothers and families feel able to support their child's needs and help them to learn and develop. A notable proportion of families report not knowing the next steps in their child's growth and learning, being unsure of their child's rights or their options beyond the ECI, and not being 
able to participate in their local community or take care of their own needs. This suggests that ECI is supporting families well in relation to their child's current needs but may need more focus on building family capacity around the child and family in relation to their understanding of likely future development, and their understanding of their rights and options. Comparatively, a greater proportion of positive responses was seen for items that included knowing their child well and functioning within their own family. The majority of families reported that their basic needs, such as food and transport, were met (which may reflect the population demographics of this sample), although some mothers had concerns about provision for medical, dental, and childcare needs.

The items in Section B provide an indication of whether mothers perceive that they have benefited from ECIs and where additional support may be required. It is important to note that this reflects mothers' perception of the helpfulness of ECI, which may or may not be directly related to their individual experience and input received. The results in this section confirm some of the findings above; mothers perceive ECI to be helpful in finding out about their child and their child's needs, but perceive that ECI was not as helpful in developing skills they require to advocate for their child and family. Advocacy for an individual in its broadest terms requires knowledge of rights, what is available, and the likely life-course trajectory for an individual. Thus, supporting parents to become strong, informed advocates may benefit children and be particularly important in the context of needs-led funding schemes such as the Australian NDIS.

It is concerning that a proportion of mothers in this study reported that they did not feel they could take part in activities in their community. Recent data indicate that children on the spectrum in Australia participate less frequently and in a narrower range of activities than children with intellectual disabilities and children without autism, and that parents would like their children to participate in more activities that involved other children (Simpson, 
Keen, Adams, Alston-Knox, \& Roberts, 2018). It may be that parents do not feel confident about how to facilitate participation and advocate effectively to remove the environmental or social barriers that have been identified as hindering participation for children on the spectrum (Egilson, Jakobsdottir, Olafsson, \& Leosdottir, 2017).

Interestingly, more than half of the mothers in this sample noted they had good support networks, but few reported being able to "completely" do the things that they enjoy. It could be argued that this is the case for many parents, especially those of children with additional needs and/or behavioural difficulties (Adams, Rose, Jackson, Karakastani \& Oliver, 2018; Adams, Clarke et al., 2018). Although there is no control group of Australian children without a diagnosis of autism to compare this item to within this study, there are three studies which have published item level data on the FOS-R from samples of children with mixed diagnoses from around the world. When the average score on this item for mothers of children on the spectrum in Australia (2.76) is compared to published data for parents of children with a range of neurodevelopmental disabilities, it is notable that the score for this sample was lower than that reported for United States (4.32; Bailey et al, 2011), Singapore (3.39; Poon et al., 2014), and Japan (3.32; Ueda et al., 2015). Although the U.S. and Singaporean samples were younger than the Australian sample, the mean age of the Japanese sample was similar, so this cannot be solely attributed to the age of the child. When coupled with the difficulties that families experience in participating in the activities they would like to engage in, as outlined above, these results may begin to explain some of the feelings of isolation commonly reported amongst families of children who have autism (Navot, Jorgenson, \& Webb, 2017). Parents of children on the spectrum frequently report building support networks with other parents of children on the spectrum, so it may be that parents gain their knowledge about rights and participation from other families rather than from ECI services (Mackintosh, Myers \& Goin-Kochel, 2005). Although this study did not 
seek to understand the sources of information, it is likely that peers and internet-based sources including social media may play key roles.

Results indicate a number of areas in which mothers perceive that ECI was less helpful, such as providing information about available options for their child when they leave the service or explaining legal rights in an easy to understand way. It may be that these areas are addressed in ECI settings but that parents and family members only receive information and education on autism as it applies to their own child on an "as-needed" basis, or that they may not digest the information if it is presented at a time when it is not of immediate importance to them.

As this Australian study sample is predominantly of middle- to high-socioeconomic status, the finding that many of the participants in this sample were engaged in multiple ECIs is unsurprising, especially given the heterogeneous nature of this population in terms of needs (McIntryre \& Zemantic, 2016). It is also consistent with previous research where the use of multiple interventions by individual children has been commonly reported, with the mean number of interventions being used simultaneously ranging from 2.6 to 7 (Carlon, Stephenson, \& Carter, 2014). However, the balance between intervention use and potential parent stress needs to be carefully managed (Shepherd et al., 2017) to avoid increased carer fatigue (Smith et al., 2010) and consequent possible reduced level of benefit from the intervention program.

Although Ueda et al. (2015) and Bailey et al. (2011) discuss and promote the use of the FOS-R at both subscale and total score level, this study highlights the importance of looking at the individual items and the distribution of the ratings. Subscale scores may mask the profile of contributing items, such as in Outcome 5 of Section A, where different items have both the highest and lowest number of mothers rating the outcome as completely attained. This study is predominantly descriptive, hence more work is needed in order to 
explore associated factors that may influence the attainment of family outcomes and the perceived helpfulness of interventions, and the way this perception may change based on child factors (such as child ability/autism characteristics) or parental factors (such as parental stress/mental health). Such knowledge will make an important contribution to our understanding regarding the outcomes of ECI, as whether families feel they benefit from services they receive is a critical factor for determining engagement with, and long-term outcomes of, ECI.

\section{Limitations and Future Directions}

These findings should be considered in the context of the study limitations. The data are from children who had been diagnosed before the age of 6 years old (the maximum age for this cohort). This may mean that these children had a more apparent presentation than those diagnosed later in their development (Daniels \& Mandell, 2013). The data were extracted from a larger sample of caregivers recruited into a 6-year longitudinal study who were predominantly from similar socioeconomic backgrounds, with high levels of tertiary education, which potentially biases the sample. All the respondents were mothers resided in Australia were where access to ECI may occur more or less frequently than in other parts of the world. It is also important to note the sample consisted of only mothers (and therefore the results may not be reflective of the experience of fathers) and there was a relatively high level of parent-diagnosed mental health disorders, which may have biased the results in terms of reporting feelings of competency in advocacy. It is also acknowledged that the larger sample from which this study is drawn may be self-selecting in some way from the larger pool of participants to whom the study was advertised (i.e. parents who wish to or are able to commit to a six-year longitudinal study).

Within this study, mothers were asked about the range of ECIs accessed but the measurement of access and/or engagement to ECI did not go into detail and was not 
independently confirmed in any way. Thus, whether mothers reported on their current or previous experiences of ECI services, and the length of time (per week or across weeks) spent engaging in these services, remain unknown. However, this needs to be considered in relation to research suggesting that the number of hours of ECI received is not predictive of outcomes (Darrou et al., 2010), and the focus of this study being on perceived family outcomes. As this study did not collect detailed information on the extent or duration of engagement with each specific ECI service, it was not possible to compare outcomes based on each type of ECI service accessed, an area that could be considered in future research. Partnering with ECI providers to collect family outcomes on a sample with a more standardised input would help to control for this in future studies, thus providing a clearer indication of family outcome attainment and the perceived helpfulness of ECI for families of children on the spectrum in the Australian context. Finally, the addition of a control group of children who have received early intervention but do not have a diagnosis of autism would also strengthen the conclusions made.

\section{Conclusion}

This study aimed to explore the profile of responses to the Family Outcome ScaleRevised (FOS-R) in a sample of Australian mothers of children on the autism spectrum who have received ECI. Based upon questionnaire responses from 96 mothers, there was variability in the outcomes reported by families of children on the spectrum and further work is needed to advance understanding of factors that may influence such outcomes. The majority of families noted their physical needs were being met and felt that ECI had been helpful in listening to them and helping them to develop an understanding of their child's needs. In contrast, ECI was not perceived to be as helpful for mothers in assisting them to understand their or their child's rights. Such understanding is likely to be increasingly 
important with changes to funding which require parents and families to develop supports and knowledge to be able to successfully advocate for their child.

Ethical approval: All procedures performed in studies involving human participants were in accordance with the ethical standards of the institutional research committees and with the 1964 Helsinki declaration and its later amendments or comparable ethical standards. 


\section{References}

Adams, D., Clarke, S., Griffith, G., Howlin, P., Moss, J., Petty, J., Tunnicliffe, P., \& Oliver, C. (2018). Mental health and wellbeing in mothers of children with genetic syndromes showing chronic challenging behavior: a cross-sectional and longitudinal study. American Journal on Intellectual and Developmental Disabilities, 123, 241-253. Doi: $10.1352 / 1944-7558-123.3 .241$

Adams, D., Handley, L., Simkiss, D., Walls E., Jones, A., Knapp M., Romeo R., \& Oliver, C. (2018). Service Use and Access in Young Children with Developmental Delay and Challenging Behavior. Journal of Intellectual and Developmental Disability, 43, 232241. doi:10.3109/13668250.2016.1238448.

Adams, D., Hastings, R., Alston-Knox, A., Cianfaglione, R., Eden, K., Felce, D., Griffith, G., Moss, J, Stinton, C. \& Oliver, C. (2018). Using Bayesian methodology to explore the profile of mental health and well-being in 646 mothers of children with 13 rare genetic syndromes in relation to mothers of children with autism. Orphanet Journal of Rare Diseases, 13, 185.

Adams, D., Rose, J. Jackson, N., Karakatsani, E., \& Oliver, C (2018). Coping strategies in mothers of children with intellectual disabilities showing multiple forms of challenging behaviour: associations with maternal mental health. Behavioural and Cognitive Psychotherapy doi: 10.1017/S1352465817000704.

Bailey, D. B., Bruder, M. B., Hebbeler, K., Carta, J., Defosset, M., Greenwood., C., Kahn, L. ... Barton, L. (2006). Recommended outcomes for families of young children with disabilities. Journal of Early Intervention, 28, 227-251.

doi:10.1177/105381510602800401 
Bailey, D., Hebeler, K., Olmsted, M., Raspa, M., \& Bruder, M. (2008). Measuring family outcomes: Considerations for large-scale data collection in early intervention. Infants \& Young Children, 23, 194-206. doi:10.1097/01.IYC.0000324549.31822.c3

Bailey, D. B., Raspa, M., Olmsted, M. G., Novak, S. P., Sam, A. M., Humphreys, B. P., Nelson, R. ... Guillen, C. (2011). Development and psychometric validation of the Family Outcomes Survey - Revised. Journal of Early Intervention, 33, 6-23. doi:10.1177/1053815111399441

Bailey, D. B., \& Simeonsson, R. J. (1988). Assessing needs of families with handicapped infants. The Journal of Special Education, 22, 117-127. doi:10.1097/DBP.0b013e3181976a95

Blacher, J., \& McIntyre, L. L. (2006). Syndrome specificity and behavioural disorders in young adults with intellectual disability: Cultural differences in family impact. Journal of Intellectual Disability Research, 50, 184-198. doi: 10.1111/j.13652788.2005.00768.x

Bruder, M. B. (2010). Early childhood intervention: A promise to children and families for their future. Exceptional Children, 76, 339-355. doi:10.1177/001440291007600306

Carlon, S., Stephenson, J., \& Carter, M. (2014). Parent reports of treatments and interventions used with children with autism spectrum disorders (ASD): A review of the literature. Australasian Journal of Special Education, 1-28. doi:10.1017/jse.2014.4

Crow, R., Gage, H., Hampson, S., Hart, J., Kimber, A., Storey, L., \& Thomas, H. (2002). The measurement of satisfaction with healthcare: Implications for practice from a systematic review of the literature. Clinical Governance: An International Journal, 8, 352. 
Daniels, A. M., \& Mandell, D. S. (2013). Explaining differences in age at autism spectrum disorder diagnosis: A critical review. Autism, 18, 583-597. doi:10.1177/13623613 13480277

Darrou, C., Pry, R., Pernon, E., Michelon, C., Aussilloux, C., \& Baghdadli, A. Outcomes of young children with autism. Autism, 14, 663-677. doi: 10.1177/1362361310374156

Davis, A. L., \& Neece, C. L. (2017). An examination of specific child behavior problems as predictors of parenting stress among families of children with pervasive developmental disorders. Journal of Mental Health Research in Intellectual Disabilities, 10, 163-177. doi: 10.1080/19315864.2016.1276988

Dempsey, I. \& Keen, D. (2008). A review of processes and outcomes in family-centered services for children with a disability. Topics on Early Childhood Special Education, $28,42-52$.

Dempsey, I., Keen, D., Pennell, D., O'Reilly, J., \& Neilands, J. (2009). Parent stress, parenting competence and family-centered support to young children with an intellectual or developmental disability. Research in Developmental Disabilities, 30, 558-566. doi:10.1016/j.ridd.2008.08.005

Dunst, C. J. (2000). Revisiting "rethinking early intervention". Topics in Early Childhood Special Education, 20, 95-104. doi:10.1177/027112140002000205

Dunst, C. J. (2002). Family-centered practices: Birth through high school. Journal of Special Education, 36, 139-147.

Duwa, S. M., Wells, C., \& Lalinde, P. (1993). Creating family-centered programs and policies. In D. M. Bryant \& M. A. Graham (Eds.), Implementing early intervention: From research to effective practice (pp. 99-123). New York: Guilford.

Egilson, S. T., Jakobsdottir, G., Olafsson, K., \& Leosdottir, T. (2017). Community participation and environment of children with and without autism spectrum disorder: 
Parent perspectives. Scandinavian Journal of Occupational Therapy, 24, 187-196. doi:10.1080/11038128.2016.1198419

Eisenhower, A. S., Baker, B. L., \& Blacher, J. (2005). Preschool children with intellectual disability: syndrome specificity, behaviour problems, and maternal well-being. Journal of Intellectual Disability Research, 49, 657-671. doi: 10.1111/j.13652788.2005.00699.x

Gavidia-Payne, S., Meddis, K., \& Maher, N. (2015). Correlates of child and family outcomes in an Australian community-based early childhood intervention program. Journal of Intellectual and Developmental Disability, 40, 57-67. doi:10.3109/13668250.2014.983056

Harrop, C., McBee, M., \& Boyd, B. A. (2016). How are child restricted and repetitive behaviors associated with caregiver stress over time? A parallel process multilevel growth model. Journal of Autism and Developmental Disorders, 46, 1773-1783. doi: $10.1007 / \mathrm{s} 10803-016-2707-7$

Hayes, S., A., \& Watson, S. L. (2013). The impact of parenting stress: A metaanalysis of studies comparing the experience of parenting stress in parents of children with and without autism spectrum disorder. Journal of Autism and Developmental Disabilities, 43, 629-642. doi: 10.1007/s10803-012-1604-y

Heller, T. Miller, A.B., \& Hsieh, K. (1999). Impact of a consumer-directed family support program on adults with developmental disabilities and their family caregivers. Family Relations, 48, 419-427

Hoffman, L., Marquis, J., Poston, D., Summers, J. A., \& Turnbull, A. (2006). Assessing family outcomes: Psychometric evaluation of the Beach Center Family Quality of Life Scale. Journal of Marriage and Family, 8, 1069-1083. doi:10.1111/j.17413737.2006.00314.x 
Hughes-Scholes, C. H., Gatt, S. L., Davis, K., Mahar, N., \& Gavidia-Payne, S. (2016). Preliminary Evaluation of the Implementation of a Routines-Based Early Childhood Intervention Model in Australia: Practitioners' Perspectives. Topics in Early Childhood Special Education, 36(1), 30-42. doi: 10.1177/0271121415589546

Jellett, R., Wood, C. E., Giallo, R., \& Seymour, M. (2015). Family functioning and behaviour problems in children with autism spectrum disorders: The mediating role of parent mental health. Clinical Psychologist, 19, 39-48. doi: $10.1111 /$ cp. 12047

Karst, J. S., \& Van Hecke, A. V. (2012). Parent and family impact of autism spectrum disorders: A review and proposed model for intervention evaluation. Clinical Child and Family Psychology Review, 15, 247-277. doi:10.1007/s10567-012-0119-6

Keen, D., Couzens, D., Muspratt, S. \& Rodger, S. (2010). The effects of a parent-focused intervention for children with a recent diagnosis of autism spectrum disorder on parenting stress and competence. Research in Autism Spectrum Disorders, 4, 229241. doi: 10.1016/j.rasd.2009.09.009

Lanners, R., \& Mombaerts, D. (2000). Evaluation of parents' satisfaction with early intervention services within and among European countries: Construction and application of a new parent satisfaction scale. Infants \& Young Children, 12, 61-70. doi:10.1097/00001163-200012030-00009

Lee, L. C., David, A. B., Rusyniak, J., Landa, R., \& Newschaffer, C. J. (2007). Performance of the Social Communication Questionnaire in children receiving preschool special education services. Research in Autism Spectrum Disorders, 1, 126-138. doi:10.1016/j.rasd.2006.08.0 04 
Mackintosh, V. H., Myers, B. K., \& Goin-Kochel, R. P. (2005). Sources of information and support used by parents of children with autism spectrum disorders. Journal of Developmental Disabilities, 12, 41-51.

McBroom, L. A., \& Enriquez, M. (2009). Review of family-centered interventions to enhance the health outcomes of children with type 1 diabetes. The Diabetes Educator, 3, 428-438. doi:10.1177/0145721709332814

McIntyre, L. L., \& Zemantic, P. K. (2016). Examining services for young children with autism spectrum disorder: Parent satisfaction and predictors of service utilization. Early Childhood Education Journal, 1-8. doi:10.1007/s10643-016-0821-y

McNaughton, D. (1994). Measuring parent satisfaction with early childhood intervention programs: Current practice, problems, and future perspectives. Topics in Early Childhood Special Education, 14, 26-48. doi:10.1177/027112149401400106

Navot, N., Jorgenson, A. G., \& Webb, S. J. (2017). Maternal experience raising girls with autism spectrum disorder: A qualitative study. Child: Care, Health and Development, 43, 536-545. doi:10.1111/cch.12470

Odom, S., \& Wolery, M. (2003). A Unified Theory of Practice in Early Intervention/Early Childhood Special Education: Evidence-Based Practices. The Journal of Special Education, 37(3), 164-173. https://doi.org/10.1177/00224669030370030601

Osbourne, L. A., McHugh, L., Saunders, J., \& Reed, P. (2008). Parenting stress reduces the effectiveness of early teaching. Journal of Autism and Developmental Disorders, 38, 1092-1103. doi: 10.1007/s10803-007-0497-7

Piotrowski, C. C., Talavera, G. A., \& Mayer, J. A. (2009). Healthy steps: A systematic review of a preventive practice-based model of pediatric care. Journal of Developmental and Behavioral Pediatrics, 30, 91-103. doi:10.1097/DBP.0b013e3181976a95 
Prior, M., \& Roberts, J. (2012). Early Intervention for Children with Autism Spectrum Disorders: Guidelines for Good Practice. Retrieved from https://www.dss.gov. au/sites/default/files/documents /08_2014/6006__accessible_early_intervention practice_guidelines_0.pdf

Poon, K. K., Ooi, N., Bull, R., \& Bailey, D. B. (2014). Psychometric validation of the Family Outcomes Survey-Revised in Singapore. Research in Developmental Disabilities, 35, 1534-1543. doi:10.1016/j.ridd.2014.03.047

Roberts, J. Adams, D., Heussler, H., Keen, D., Paynter, J., Trembath, D., Westerveld, M. \& Williams, K. (2018). Protocol for a prospective longitudinal study investigating the participation and educational trajectories of Australian students with autism. BMJ Open, 8, e017082.

Rutter, M., Bailey, A., Berument, S., Lord, C., \& Pickles, A. (2003). Social communication questionnaire. Los Angeles, CA: Western Psychological Services.

Sarimski, K., Hintermair, M., \& Lang, M. (2013). Parent stress and satisfaction with early intervention services for children with disabilities: A longitudinal study from Germany. European Journal of Special Needs Education, 28, 362-373. doi:10.1080/08856257.2013.797706

Shepherd, D., Landon, J., \& Goedeke, S. (2017). Symptom severity, caregiver stress and intervention helpfulness assessed using ratings from parents caring for a child with autism. Autism, 1-12. doi:10.1177/1362361316688869

Simpson, K., Keen, D., Adams, D., Alston-Knox, C., \& Roberts, J. (2018). Participation of children on the autism spectrum in home, school and community. Child: Care, Health and Development, 44, 99-107. doi: 10.1111/cch.12483.

Smith, L. E., Hong, J., Selzer, M., Greenberg, J. S., Almeida, D., \& Bishop, S. L. (2010). Daily experiences among mothers of adolescents and adults with autism spectrum 
disorder. Journal of Autism and Developmental Disorders, 40, 167-178.

doi:10.1007/s10803-009-0844-y

Sukkar, H (2013). Early Childhood Intervention: An Australian Perspective. Infants \& Young Children, 26, 94-110.

Ueda, K., Yonemoto, N., \& Bailey Jr, D. B. (2015). Psychometric validation of the Family Outcomes Survey-Revised in Japan. Research in Developmental Disabilities, 39, 5566. doi:10.1016/j.ridd.2015.01.003

Vivanti, G., Kasari, C., Green, J., Mandell, D., Maye, M., \& Hudry, K. (2017). Implementing and evaluating early intervention for children with autism: Where are the gaps and what should we do? Autism Research. doi:10.1002/aur.1900

Zaidman-Zait, A., Mirenda, P., Duku, E., Szatmari, P., Georgiades, S., Volden, J., Zwaigenbaum, L.,...Thompson, A. (2014). Examination of bidirectional relationships between parent stress and two types of problem behavior in children with autism spectrum disorder. Journal of Autism and Developmental Disorders, 44, 1908-1917. doi: 10.1007/s10803-014-2064-3

Zwaigenbaum, L., Bauman, M. L., Choueiri, R., Kasari, C., Carter, A., Granpeesheh, D., ... Natowicz, M. R. (2015). Early intervention for children with autism spectrum disorder under 3 years of age: Recommendations for practice and research. Pediatrics, 136 Suppl 1, S60-81. doi:10.1542/peds.2014-3667E 